P ISSN 2356-1637 | E ISSN 2581-0103

https://journal.iainlangsa.ac.id/index.php/qadha

https://doi.org/10.32505/qadha.v7i2.1962

\title{
TRADISI REBU NGERANA PASCA PERKAWINAN PADA MASYARAKAT KARO SUMATERA UTARA PERSPEKTIF ‘URF
}

\author{
A. Millati Azka. A. M \\ Fakultas Syariah dan Hukum, UIN Sunan Kalijaga Yogyakarta \\ millatiazka789@gmail.com
}

\begin{abstract}
Rebu ngerana is a tradition that limits communication between three parties, including male and female in-laws, female in-laws with son-in-law, and fellow in-laws of different sexes. The purpose of this study is to analyze the meaning of the reconstructed tradition and its relationship with Islamic law. The method used is juridical empirical with the 'urf approach. The results of this study can be understood that the Karo people understand the tradition of rebu ngerana as an ancestral tradition that should be preserved because it has its own value in household life. However, in its current implementation, the Karo community in Ujung Teran village only imposes a tradition on their brother in-law to remind people to be aware of social principles in the way of life in a relationship. Meanwhile, in the view of 'urf, the rebu ngerana tradition is included in the category of 'urf sahih. So that it can be understood that this tradition has a relationship with the essence of marriage, namely maintaining self and family.
\end{abstract}

Keywords: Tradition, Rebu Ngerana, 'Urf.

\begin{abstract}
Abstrak
Rebu ngerana merupakan sebuah tradisi yang membatasi berkomunikasi antara tiga pihak diantaranya mertua laki-laki dan menantu perempuan, mertua perempuan dengan menantu laki-laki, dan sesama ipar yang berjenis kelamin berbeda. Tujuan penelitian ini yaitu untuk menganalisis makna tradisi rebu ngerana dan relasinya dengan hukum Islam. Metode yang digunakan yaitu yuridis empiris dengan pendekatan 'urf. Hasil dari penelitian menunjukan bahwa masyarakat Karo memahami tradisi rebu ngerana sebagai tradisi nenek moyang yang harus dilestarikan karena memiliki nilai tersendiri dalam kehidupan rumah tangga. Namun, dalam pelaksanaannya saat ini masyarakat Karo di Desa Ujung Teran hanya memberlakukan tradisi kepada saudara ipar untuk mengingatkan orang agar sadar
\end{abstract}


terhadap prinsip sosial dalam cara hidup berkerabat. Dalam kontek 'urf tradisi rebu ngerana masuk dalam 'urf sahih. Sehingga dapat dipahami bahwa tradisi ini memiliki keterkaitan dengan esensi filosofis perkawinan yakni menjaga diri dan keluarga.

Kata Kunci: Tradisi, Rebu Ngerana, 'Urf.

\section{Pendahuluan}

Kebudayaan mencakup pengetahuan, kepercayaan, kesenian, moral hukum, adat istiadat dan kemampuan-kemampuan yang didapatkan oleh manusia sebagai anggota masyarakat. ${ }^{1}$ Menurut ilmu sosiologi, konsep kebudayaan (culture) sangat penting, karena obyek studi pokok sosiologi adalah masyarakat. Suatu masyarakat tidak dapat dipisahkan dari suatu kebudayaan, sebagaimana menurut Harton dan Hun bahwa antara masyarakat dan kebudayaan memiliki hubungan dalam sistem norma dan nilai. ${ }^{2}$ Sama seperti perkawinan, dalam konteks sosial perkawinan menjadi salah satu objek kajian, karena perkawinan akan membentuk hubungan sosial dan kelompok masyarakat kecil yang disebut keluarga.

Perkawinan merupakan peristiwa penting dalam kehidupan setiap manusia. Selain menjalankan perintah Allah serta sunnah Rasulullah SAW, perkawinan merupakan suatu jembatan yang akan melahirkan generasi penerus zaman dan kebudayaan. ${ }^{3}$ Adanya perkawinan menyebabkan bersatunya laki-laki dan perempuan sekaligus dua buah keluarga yaitu keluarga pihak laki-laki dan keluarga pihak perempuan. Adanya hubungan perkawinan menjadikan persatuan antar pihak yang sama-sama memiliki orangtua baru yang disebut dengan mertua. 4 Sebaliknya, orangtua dari kedua mempelai juga sama-sama memiliki anak baru yang disebut dengan menantu.

Adanya pembentukan keluarga baru setelah menikah mengakibatkan perubahan pada pola kekeluargaan. Perubahan tersebut berupa peralihan kewajiban yang semula masih menjadi tanggungjawab orangtua masing-masing, ketika sudah menikah maka beralih kepada pasangannya. Seorang wanita setelah menikah memiliki kewajiban tidak hanya kepada pasangan melainkan juga kepada mertua. ${ }^{5}$ Begitu juga sebaliknya, seorang laki-laki setelah menikah tidak hanya memiliki kewajiban kepada pasangan

\footnotetext{
${ }^{1}$ Soerjono Soekanto, Sosiologi: Suatu Pengantar, 43rd ed. (Jakarta: Raja Grafindo Persada, 2010).266

${ }^{2}$ Koentjaraningrat, Kebudayaan, Mentalitas Dan Pembangunan (Jakarta: Gramedia Pustaka Utama, 1999).37-38

3Imam Budhi Santoso, Petuah-Petuah Bijak Para Leluhur Nusantara Seputar Perkawinan (Yogyakarta: Laksana, 2011). 5

4"17 Adab Mertua Terhadap Menantu - DalamIslam.Com," accessed December 12, 2020, https://dalamislam.com/hukum-islam/pernikahan/adab-mertua-terhadap-menantu.

5“17 Kewajiban Menantu Wanita Terhadap Mertua," DalamIslam.com, November 13, 2017, https://dalamislam.com/info-islami/kewajiban-menantu-wanita-terhadap-mertua.
} 
saja melainkan juga kepada orangtua dan mertuanya. Tidak hanya itu saja, perubahan juga terjadi pada pola sikap dan adat, seperti yang terjadi pada suku Karo.

Pada masyarakat suku Karo, pernikahan turut mempengaruhi pola komunikasi antara menantu dan mertua yang disebut dengan istilah tradisi rebu ngerana. Menurut Sartika dalam penelitiannya menjelaskan bahwa tradisi rebu merupakan suatu larangan komunikasi langsung antara beberapa pihak seperti menantu dan mertua. Namun adanya larangan komunikasi antara mertua dan menantu ini tidak menjadikan komunikasi antar keduanya terputus. Berdasarkan hubungan yang secara umum terjadi antara mertua dan menantu, dapat dikatakan bahwa untuk menjalin keharmonisan diantara keduanya dibutuhkan komunikasi interpersonal. Komunikasi interpersonal memiliki manfaat agar menantu dan mertua saling terbuka untuk mencapai kesepakatan bersama sehingga terjalin sebuah hubungan yang harmonis. ${ }^{6}$

Dalam memahami tradisi rebu, masyarakat Karo menganggap sebagai hubungan sungkan. Namun, Saat ini tradisi rebu disebutkan Jepri mengalami kelunturan budaya. Penyebabnya adalah adanya perubahan dan tuntutan zaman yang memaksa masyarakat Karo untuk lebih menekankan nilai kemanusiaan dari pada nilai adat istiadat dan keagamaan. ${ }^{7}$ Pengaplikasian budaya rebu dalam penelitian Rivira dijelaskan dapat dipengaruhi pada wilayah dan tempat tinggal. Semakin sedikit masyarakat yang tinggal di wilayah dengan budaya tradisi rebu, maka semakin sedikit pula yang mengaplikasikan tradisi. ${ }^{8}$

Sardis Br. Ginting dalam penelitiannya juga menambahkan bahwa faktor utama penyebab pergeseran tradisi rebu pada masyarakat Karo terbagi menjadi dua: Pertama, dari dalam masyarakat disebabkan karena beberapa masyarakat yang kurang memahami tradisi rebu, kurangnya sosialisasi dalam masyarakat, dan hilangnya nilai budaya; Kedua, dari luar masyarakat disebabkan karena arus modernisasi dan globalisasi, lingkungan, perkawinan campur, ekonomi, dan faktor politik. ${ }^{9}$

Terlepas dari penelitian-penelitian sebelumnya yang menyatakan adanya pergeseran tradisi di beberapa wilayah tertentu, Desa Ujung Teran merupakan salah satu wilayah yang masih menerapkan tradisi rebu sampai saat ini. Ujung Teran

\footnotetext{
${ }^{6}$ Wiwik Sulistyaningsih and Sartika, "Gambaran Komunikasi Interpersonal Menantu Dan Mertua Yang Menggunakan Adat Rebu Di Budaya Karo," PREDICARA 1, no. 2 (2012): 81-85.

7 Jepri Andi Sinuraya and Waston Malau, "Rebu dalam Sistem Kekerabatan Etnis Batak Karo di Desa Lingga Kecamatan Simpang Empat Kabupaten Karo," Gondang: Jurnal Seni dan Budaya 3, no. 1 (June 1, 2019): 35-49, https://doi.org/10.24114/gondang.v3i1.13018.

8 Rivira Tania S.B and Diah Agung E, "Analisis Pengaplikasian Adat Rebu Pada Masyarakat Karo," Liski 1, no. 1 (2015): 1-11.

9 Sardis Br Ginting, La Niampe, and La Ode Topo Jers, "Rebu: Tradisi Pantangan bagi Suku Karo," ETNOREFLIKA: Jurnal Sosial dan Budaya 9, no. 1 (February 28, 2020): 62-70, https://doi.org/10.33772/etnoreflika.v9i1.725.
} 
merupakan salah satu Desa yang ada di Kecamatan Merdeka Kabupaten Karo, Sumatera Utara. Menurut populasi penduduk Desa Ujung Teran tahun 2020 disebutkan sebanyak 1250 jiwa dengan rincian masyarakat yang sudah menikah sebanyak 40\% dan yang belum menikah 60\%, sehingga total terdapat 250 pasangan yang sudah berumah tangga. ${ }^{10}$ Pendapat masyarakat Desa Ujung Teran terhadap tradisi rebu, dikatakan bahwa tradisi ini berlaku atas tiga pihak yaitu antara menantu perempuan dengan mertua laki-laki, menantu laki-laki dengan mertua perempuan, dan sesama ipar yang berjenis kelamin berbeda. ${ }^{11}$

Melalui keterangan yang disampaikan, perlu diketahui bahwa masyarakat di Desa Ujung Teran merupakan masyarakat Karo asli. Sehingga tradisi-tradisi nenek moyang masih terjadi bahkan ketat dilaksanakan. Sebagaimana yang dipahami sebelumnya, dalam perkawinan terdapat dua keluarga yang menjadi satu karena adanya hubungan perkawinan. Sehingga dengan demikian, dalam dua keluarga terdapat hubungan baru yakni mertua, menantu, dan saudara ipar yang bahkan berjenis kelamin berbeda. Alasan untuk menganalisa bagaimana penerapan tradisi rebu dalam menjaga keharmonisan antar dua keluarga menurut Islam, disebabkan bahwa dalam Islam terdapat hal yang berkaitan dengan 'urf.

'Urf dalam Islam merupakan suatu kebiasaan mayoritas manusia dalam penilaian suatu perkataan atau perbuatan. Menurut pembagiannya dari segi keabsahan, 'urf terbagi menjadi dua yakni 'urf shahih dan 'urf fasid. 'Urf sahih adalah kebiasaan yang berlaku dalam masyarakat yang tidak bertentangan dengan nash, tidak menghilangkan kemaslahatan, dan tidak membawa kemudharatan. Sedangkan 'urf fasid merupakan kebiasaan yang bertentangan dengan dalil syara' dan kaidah dasar yang ada dalam syara'.12

Berdasarkan penjelasan tersebut diatas, penulis memfokuskan penelitian dalam kajian bagaimana makna tradisi rebu ngerana pada masyarakat karo di Desa Ujung Teran dan bagaimana kajian 'urf melihat tradisi rebu ngerana. Apakah terdapat relasi kuat antara hukum Islam dan adat dalam tradisi rebu ngerana.

Untuk mengkaji hal tersebut, penelitian ini menggunakan pendekatan kualitatif yang bersifat deskriptif analitis. Partisipan dalam penelitian ini berjumlah lima orang yang terdiri dari satu orang perangkat Desa, satu orang pemuka agama, dan tiga masyarakat Desa Ujung Teran yang statusnya terdiri dari menantu, mertua dan ipar. Pengumpulan data dalam penelitian ini dilakukan dengan observasi dan wawancara mendalam dengan para informan secara langsung dan tidak langsung (online). Alasan

\footnotetext{
10 Rina, Wawancara Perangkat Desa Ujung Teran, February 20, 2020.

${ }^{11}$ Arifin, Wawancara Pemuka Agama Desa Ujung Teran, February 20, 2020.

${ }^{12}$ Abdul Aziz Dahlan, Ensiklopedia Hukum Islam, 5th ed. (Jakarta: PT. Ichtiar Baru van Hoeve, 2001).1877
} 
menggunakan dua metode seperti wawancara dan observasi; 1) observasi merupakan suatu cara untuk mengeksplorasi isu dari tradisi rebu pada masyarakat Karo di Desa Ujung Teran yang masih berjalan hingga saat ini; 2) wawancara merupakan suatu pelengkap dari tindakan observasi lapangan berupa percakapan dan tanya jawab yang diarahkan untuk menjawab permasalahan terkait makna tradisi rebu ngerana pada masyarakat Karo di Desa Ujung Teran Sumatera Utara.

\section{Pemahaman Rebu Ngerana pada Masyarakat Karo Desa Ujung Teran}

Tradisi rebu ngerana sebenarnya dijelaskan sudah ada sejak zaman nenek moyang masyarakat Karo dan masih berlaku hingga saat ini oleh beberapa masyarakat di wilayah yang masih kental nuansa adat. ${ }^{13}$ Secara istilah, rebu memiliki arti dilarang berbicara dan dapat disamakan dengan adat sopan santun. Dalam bahasan Karo, rebu adalah sesuatu yang dianggap suci berkaitan dengan sopan santun, larangan, pantangan, tidak bebas atau sesuatu yang dibatasi. ${ }^{14}$ Adat sopan santun pada dasarnya ialah segala tingkah laku, perilaku, adat istiadat, tegur sapa, ucapan, dan cakap yang sesuai dengan kaidah atau norma tertentu. Tradisi rebu menjadi pola bagi kelakuan sosial warga masyarakat karena mengandung nilai-nilai, aturan-aturan, ide-ide, dan keyakinan yang secara keseluruhan merupakan pedoman bertindak dan bertingkah laku bagi setiap warga masyarakatnya. ${ }^{15}$

Menurut sejarahnya, tradisi rebu ngerana terbentuk karena pada zaman dahulu bentuk rumah Karo adalah "rumah si waluh jabu" dimana tiap keluarga pada masyarakat Karo hidup bersama di dalam rumah adat. dalam satu rumah adat, bisa ditempati oleh banyak keluarga tergantung luasnya. Ada yang ditempati empat, enam, atau bahkan delapan keluarga dalam satu rumah. Dari beberapa keluarga tersebut terdiri dari orangtua, anak-anak beserta cucu-cucunya, besan dan anak-anaknya yang lain, saudara kandung dan anak-anaknya, atau yang lainnya. Semuanya hidup bersama tanpa ada sekat yang memisahkan antar rumah. ${ }^{16}$

\footnotetext{
13 Wawancara Pemuka Agama Desa Ujung Teran.

${ }^{14}$ A. S. Depari, "Sistem Sosial Masyarakat Suku Karo," accessed December 12, 2020, https://www.academia.edu/19733202/Sistem_Sosial_Masyarakat_Suku_Karo.

15 Ahmad Yunus et al., Makna Pemakaian Rebu Dalam Kehidupan Kekerabatan Orang Batak Karo (Jakarta: Departemen Pendidikan dan Kebudayaan, 1994).3

${ }^{16}$ Edi, "Tradisi Rebu Jaga Keharmonisan Keluarga," accessed December 12, 2020, http://www.ediginting.com/2012/06/rebu-jaga-keharmonisan-keluarga.html.
} 


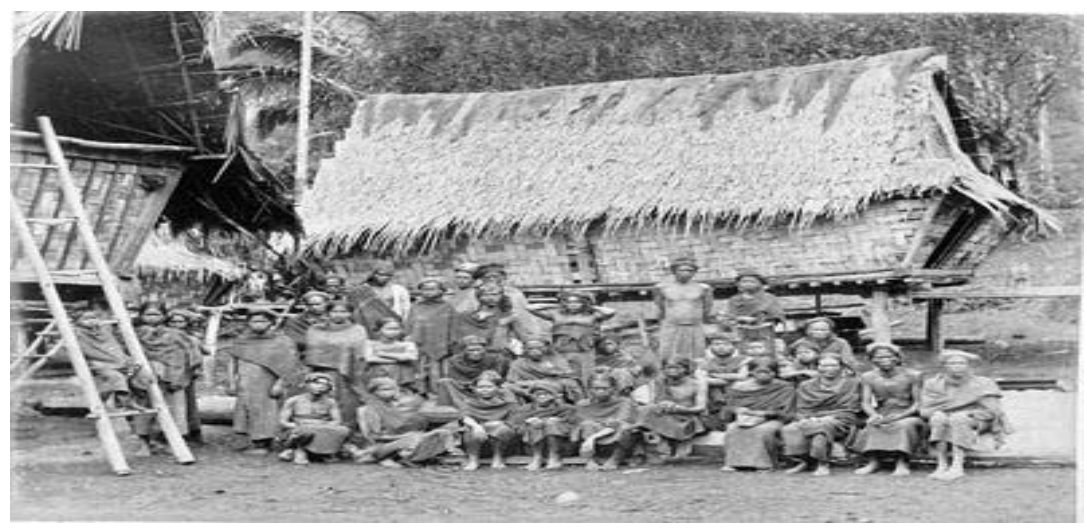

Gambar.1 Rumah Si Waluh Jambu.

Beberapa pihak yang terkait dengan tradisi rebu ngerana ini ada tiga yakni, antara menantu perempuan dengan mertua laki-laki, mertua laki-laki dengan menantu perempuan, dan sesama ipar yang berjenis kelamin berbeda. ${ }^{17}$ Adapun secara umum, tradisi rebu pada masyarakat Karo sebenarnya terbagi dalam lima macam dan memiliki pengertian berbeda di setiap tradisinya, hal tersebut diantaranya: 18

1. Rebu Ngerana; yakni batasan dalam berbicara.

2. Rebu La Arus; yakni larangan mengikat hubungan asmara antara pemuda pemudi yang bermarga sama.

3. Rebu TapinLau; yakni larangan mandi bersama di tempat pemandian antara orang-orang yang menurut adat terdapat hubungan beripar.

4. Rebu Erdahin; yakni pantangan melakukan pekerjaan selama empat hari setelah menanam padi.

5. Rebu Api; yakni larangan bersetubuh antara suami isri yang baru melahirkan.

Atas pembagian lima macam tradisi rebu pada masyarakat Karo tersebut dapat dipahami bahwa rebu ngerana merupakan salah satu tradisi rebu yang dianggap penting. Khusus pada pengertian rebu, dalam bahasa karo disebut sebagai hal suci yang berkaitan dengan sopan santun, larangan, pantangan, tidka bebas atau sesuatu yang dibatasi. Mulai berlakunya tradisi rebu ngerana dijelaskan dapat terjadi apabila sebuah perkawinan telah selesai dilaksanakan, sehingga tiga pihak yang disebutkan sebelumnya seperti mertua, menantu dan saudara ipar memiliki ketentuan adat untuk tidak berkomunikasi secara langsung. Tidak hanya rebu dalam berkomunikasi,

\footnotetext{
${ }^{17}$ Sulistyaningsih, "Gambaran Komunikasi Interpersonal Menantu Dan Mertua Yang Menggunakan Adat Rebu Di Budaya Karo."83

18 Depari, "Sistem Sosial Masyarakat Suku Karo."
} 
bahkan untuk tatapan mata, duduk diatas satu tikar yang sama, bersentuhan juga dilarang bagi mertua, menantu dan antar ipar yang berbeda jenis kelamin. ${ }^{19}$

Tradisi ini dipahami sebagai suatu tanda adanya batas kebebasan diri, melalui perilaku dalam tradisi rebu ngerana maka akan mengingatkan orang agar sadar terhadap prinsip sosial dalam cara hidup berkerabat. Rebu menimbulkan mehangke (rasa enggan), dari enggan menimbulkan rasa hormat sehingga kemudian menimbulkan adanya sopan santun. ${ }^{20}$

Adapun terhadap tradisi rebu ngerana, sanksi yang akan didapat oleh masyarakat yang tidak menjalankan berupa pencemoohan dan sanksi sosial. Hal ini disebabkan karena masyarakat Karo menganggap orang yang tidak menjalankan tradisi rebu ngerana ini sebagai orang yang tidak menuruti kebiasaan yang berlaku. ${ }^{21}$

Bagi masyarakat Desa Ujung Teran, tradisi rebu ngerana ini tidak seketat dahulu yang benar-benar tidak membolehkan berbicara, bertatap muka dan lain sebagainya. Saat ini menantu laki-laki kepada mertua perempuan dan sebaliknya boleh berbicara langsung tanpa perantara, namun dengan catatan dalam keadaan rame atau bersama dengan keluarga besar. ${ }^{22}$ Bahkan saat ini tradisi rebu ngerana ini hanya diberlakukan kepada saudara ipar yang berbeda jenis kelamin. Hal ini disebabkan karena masyarakat karo di Desa Ujung Teran sudah banyak menganut agama. Sehingga dengan pemahaman yang ada dalam agama, masyarakat mengetahui bahwa mertua termasuk salah satu orangtua yang seharusnya diperlakukan sama dengan orangtua kandung. ${ }^{23}$ Pendapat ini pun dibenarkan oleh salah satu perangkat Desa Ujung Teran, bahwa bentuk batasan komunikasi yang ada dalam tradisi rebu ngerana akhirnya hanya berlaku pada saudara ipar saja. ${ }^{24}$

\section{Tradisi Rebu Ngerana Pasca Perkawinan Perspektif 'Urf}

Tradisi rebu ngerana merupakan suatu adat istiadat yang telah terjadi sejak zaman nenek moyang Karo. Ulama usul fikih membedakan antara adat dan 'urf. Adat didefinisikan sebagai suatu perbuatan yang dikerjakan secara berulang-ulang tanpa hubungan rasional. Sementara 'urf adalah kebiasaan mayoritas umat, baik dalam perkataan maupun perbuatan. ${ }^{25}$ Tradisi rebu ngerana seperti yang telah dijelaskan sebelumnya merupakan tradisi yang terjadi setelah adanya perkawinan. Berdasarkan objek kajian dalam tradisi ini, pihak-pihak yang jadi sasaran awalnya adalah antara

\footnotetext{
${ }^{19}$ Asni, Wawancara Masyarakat Desa Ujung Teran, February 20, 2020.

${ }^{20}$ Sulistyaningsih, "Gambaran Komunikasi Interpersonal Menantu Dan Mertua Yang Menggunakan Adat Rebu Di Budaya Karo."83

21 Tania S.B and Agung E, “Analisis Pengaplikasian Adat Rebu Pada Masyarakat Karo." 8

22 Musliadi Sinulingga, Wawancara Masyarakat Desa Ujung Teran, April 12, 2019.

23 Wawancara Pemuka Agama Desa Ujung Teran.

24 Wawancara Perangkat Desa Ujung Teran.

${ }^{25}$ Aziz Dahlan, Ensiklopedia Hukum Islam.1877
} 
mertua dan menantu. Namun, secara praktek di masyarakat Desa Ujung Teran, tradisi ini mengalami pergeseran sehingga tradisi rebu ngerana saat ini hanya diperuntukkan untuk saudara ipar saja.

Dalam Islam, suatu kebiasaan yang sudah diyakini oleh mayoritas orang baik berupa perkataan maupun perbuatan yang sudah terjadi berulang-ulang dan dapat diterima oleh akal manusia disebut dengan ' $u r f .{ }^{26}$ Berdasarkan pengertian ini, tradisi rebu ngerana termasuk dalam kategori 'urf dikarenakan tradisi ini merupakan tradisi yang sudah dilakukan secara berulang-ulang sejak zaman nenek moyang masyarakat Karo, sehingga masyarakat Desa Ujung Teran tradisi ini memiliki nilai tersendiri dalam kehidupan mereka dan dapat diterima oleh akal.

Segala sesuatu yang dapat dikategorikan menjadi 'urf yang bisa diterima oleh hukum Islam memiliki beberapa syarat diantaranya: ${ }^{27}$

1. Tidak ada dalil yang khusus untuk kasus tersebut baik dalam Al-Qur'an maupun Sunnah.

2. Pemakaiannya tidak mengakibatkan dikesampingkannya nash syariah termasuk juga tidak mengakibatkan kemafsadatan, kesempitan dan kesulitan.

3. Telah berlaku secara umum dalam arti bukan hanya yang bisa dilakukan oleh beberapa orang saja.

Berdasarkan tiga syarat tersebut, tradisi rebu ngerana diketahui tidak memiliki dalil khusus dalam al-Qur'an maupun Sunnah. Adapun tradisi ini telah dilakukan oleh hampir semua masyarakat Desa Ujung Teran karena mereka memahami bahwa tradisi rebu ngerana merupakan suatu tradisi yang memiliki nilai kesopanan dalam menjaga hubungan baik antar keluarga. Namun, dalam pelaksanaannya tradisi ini dinilai dapat mengakibatkan kemafsadatan jika sasarannya antara mertua dan menantu. Sebagaimana diketahui, mertua merupakan salah satu orangtua yang perlu diperlakukan sama dengan orangtua kandung. Sehingga dalam mengatasi hal ini, masyarakat Desa Ujung Teran saat ini hanya memberlakukan sasaran tradisi hanya kepada saudara ipar.

Ketika ditinjau dari sisi kualitas/keabsahan 'urf yang terdiri dari 'urf sahih dan 'urf fasid, tradisi rebu ngerana ini dapat dikategorikan ke dalam 'urf yang sahih. Sebagaimana diketahui 'urf sahih merupakan sesuatu yang telah saling dikenal oleh manusia dan tidak bertentangan dengan dalil syara', tidak menghalalkan yang haram dan tidak membatalkan yang wajib. ${ }^{28}$ Berdasarkan pengertian ini tradisi rebu ngerana

\footnotetext{
${ }^{26}$ Aziz Dahlan. 1877

${ }^{27}$ Ahmad Djazuli, Ilmu Fiqh (Penggalian, Perkembangan, Dan Penerapan Hukum Islam) (Jakarta: Kencana Prenada Media Group, 2005).89

${ }^{28}$ Rachmat Syafe'i, Ilmu Ushul Fiqih, 4th ed. (Bandung: Pustaka Setia, 2010).129
} 
merupakan suatu tradisi yang dapat dipahami bahwa antar beberapa pihak ada sebuah batasan komunikasi sehingga nilai kesopanan dapat terjaga.

Dilihat dari ruang lingkup berlakunya/jangkauannya 'urf yang terbagi ke dalam 'urf 'amm dan 'urf khass, ${ }^{29}$ tradisi rebu ngerana termasuk ke dalam 'urf khass. Hal ini disebabkan karena pelaksanaan tradisi rebu ngerana hanya berlaku kepada masyarakat yang berasal dari Karo. Meski banyaknya masyarakat Karo yang melakukan perantauan ke beberapa wilayah di tanah Jawa menjadikan tradisi rebu ngerana mulai terkikis karena pengaruh sedikitnya masyarakat Karo yang tinggal di wilayah Karo.

Sedangkan jika dilihat dari sisi objek dari 'urf yang terdiri dari 'urf qauli dan 'urf 'amali, maka tradisi rebu ngerana merupakan jenis 'urf 'amali. Tradisi ini dikategorikan sebagai 'urf 'amali disebabkan dalam tradisi rebu ngerana melibatkan adanya perbuatan atau muamalah antar manusia. Hal ini dapat dilihat bahwa tradisi rebu ngerana merupakan suatu perbuatan untuk tidak berkomunikasi atau saling sapa secara langsung antar beberapa pihak yang memiliki hubungan keluarga karena adanya perkawinan.

Kaitannya dengan esensi perkawinan, tradisi rebu ngerana diketahui berlaku setelah perkawinan. Adapun dalam perkawinan terdapat beberapa prinsip dasar dalam kehidupan keluarga yakni setidaknya ada empat. Pertama, kehidupan berdasarkan moral agama; Kedua, menjaga kehormatan diri dan keluarga; Ketiga, seorang dari pasangan mempunyai seorang partner pasangan (monogami); Keempat, perkawinan sebagai ibadah. ${ }^{30}$

Melihat prinsip perkawinan tersebut, menjaga kehormatan diri dan keluarga memiliki kesamaan dengan menjaga keharmonisan rumah tangga. Keharmonisan rumah tangga, selain harus menghadapi beberapa cara dan prinsip perkawinan yang ada sebagai pasangan suami istri juga melewati lika liku kehidupan yang terjal. Dari lika liku yang terjal itulah para pasangan harus mewaspadai diri untuk tidak terpengaruh budaya luar. Seperti yang dijelaskan salah satu artikel bahwa keharmonisan rumah tangga bisa terancam karena adanya faktor dari luar diantaranya: a) setan; b) orang yang iri dan tidak suka melihat keharmonisan rumah tangga yang lain; c) bermudah-mudah dengan ipar, mertua; d) pergaulan yang tidak selektif. ${ }^{31}$

\footnotetext{
${ }^{29}$ Aziz Dahlan, Ensiklopedia Hukum Islam.1877

${ }^{30}$ Khoiruddin Nasution, Hukum Perkawinan Dan Warisan Di Dunia Muslim Modern (Yogyakarta: Yogyakarta: ACAdeMIA, 2012).282

${ }^{31}$ Abdul Mu'thi, "Bahaya yang Mengancam Keharmonisan Rumah Tangga," Majalah Islam Asy-Syariah (blog), March 3, 2013, https://asysyariah.com/bahaya-yang-mengancam-keharmonisan-rumahtangga/.
} 
Saudara ipar dan mertua termasuk salah satu faktor penyebab terganggunya keharmonisan rumah tangga. Adanya tradisi rebu ngerana yang ada pada masyarakat Karo menjadikan hubungan masing-masing memiliki batasan dalam berkomunikasi sehingga dapat terhindar dari faktor yang dapat merusak rumah tangga. hikmah dari adanya tradisi rebu ngerana yang melarang bentuk komunikasi langsung antara mertua, menantu dan saudara ipar ini adalah agar sistem kekeluargaan dapat berjalan lancar secara harmonis.

\section{Penutup}

Berdasarkan pembahasan tersebut diatas, dapat diketahui bahwa masyarakat Desa Ujung Teran memahami tradisi rebu ngerana sebagai tradisi nenek moyang yang patut dilestarikan karena memiliki nilai tersendiri dalam kehidupan rumah tangga. Hanya saja dalam pelaksanaannya saat ini, tradisi rebu ngerana memiliki pergeseran yakni hanya berlaku kepada saudara ipar saja. Hal ini disebabkan, saat ini masyarakat Karo di Desa Ujung Teran sudah memeluk agama sehingga lebih memahami bahwa hubungan dengan mertua sama saja dengan hubungan dengan orangtua kandung. Sementara saudara ipar, tradisi ini masih diberlakukan untuk mengingatkan orang agar sadar terhadap prinsip sosial dalam cara hidup berkerabat. Rebu menimbulkan mehangke (rasa enggan), dan dari enggan menimbulkan rasa hormat sehingga kemudian menimbulkan adanya sopan santun.

Sementara itu dalam pandangan 'urf, tradisi ini merupakan tradisi yang dibenarkan dalam Islam. Kategori 'urf sahih yang disandingkan dengan tradisi rebu ngerana, dapat dipahami bahwa tradisi ini menjaga hubungan antar beberapa pihak yang berlaku atasnya batasan komunikasi sehingga nilai kesopanan dapat terjaga. Selain itu, karena pelaksanaan tradisi rebu ngerana terjadi setelah adanya perkawinan maka dapat dipahami bahwa tradisi ini memiliki keterkaitan dengan esensi perkawinan yakni menjaga diri dan keluarga.

\section{Daftar Pustaka}

Aziz Dahlan, Abdul. Ensiklopedia Hukum Islam. 5th ed. Jakarta: PT. Ichtiar Baru van Hoeve, 2001.

Depari, A. S. "Sistem Sosial Masyarakat Suku Karo." Accessed December 12, 2020. https://www.academia.edu/19733202/Sistem_Sosial_Masyarakat_Suku_Karo.

Djazuli, Ahmad. Ilmu Fiqh (Penggalian, Perkembangan, Dan Penerapan Hukum Islam). Jakarta: Kencana Prenada Media Group, 2005.

Edi. “Tradisi Rebu Jaga Keharmonisan Keluarga.” Accessed December 12, 2020. http://www.ediginting.com/2012/06/rebu-jaga-keharmonisan-keluarga.html. 
Ginting, Sardis Br, La Niampe, and La Ode Topo Jers. "Rebu: Tradisi Pantangan bagi Suku Karo." ETNOREFLIKA: Jurnal Sosial dan Budaya 9, no. 1 (February 28, 2020): 62-70. https://doi.org/10.33772/etnoreflika.v9i1.725.

Koentjaraningrat. Kebudayaan, Mentalitas Dan Pembangunan. Jakarta: Gramedia Pustaka Utama, 1999.

Mu'thi, Abdul. "Bahaya yang Mengancam Keharmonisan Rumah Tangga." Majalah Islam Asy-Syariah (blog), March 3, 2013. https://asysyariah.com/bahaya-yangmengancam-keharmonisan-rumah-tangga/.

Nasution, Khoiruddin. Hukum Perkawinan Dan Warisan Di Dunia Muslim Modern. Yogyakarta: Yogyakarta: ACAdeMIA, 2012.

Rina. Wawancara Perangkat Desa Ujung Teran, February 20, 2020.

Santoso, Imam Budhi. Petuah-Petuah Bijak Para Leluhur Nusantara Seputar Perkawinan. Yogyakarta: Laksana, 2011.

Sinulingga, Musliadi. Wawancara Masyarakat Desa Ujung Teran, April 12, 2019.

Sinuraya, Jepri Andi, and Waston Malau. "Rebu dalam Sistem Kekerabatan Etnis Batak Karo di Desa Lingga Kecamatan Simpang Empat Kabupaten Karo.” Gondang: Jurnal Seni dan Budaya 3, no. 1 (June 1, 2019): 35-49. https://doi.org/10.24114/gondang.v3i1.13018.

Soekanto, Soerjono. Sosiologi: Suatu Pengantar. 43rd ed. Jakarta: Raja Grafindo Persada, 2010.

Sulistyaningsih, Wiwik, and Sartika. "Gambaran Komunikasi Interpersonal Menantu Dan Mertua Yang Menggunakan Adat Rebu Di Budaya Karo." PREDICARA 1, no. 2 (2012): 81-85.

Syafe'i, Rachmat. Ilmu Ushul Fiqih. 4th ed. Bandung: Pustaka Setia, 2010.

Tania S.B, Rivira, and Diah Agung E. "Analisis Pengaplikasian Adat Rebu Pada Masyarakat Karo." Liski 1, no. 1 (2015): 1-11.

Yunus, Ahmad, Siti Maria, Kencana S, and Elizabeth T. Gurning. Makna pemakaian rebu dalam kehidupan kekerabatan orang Batak Karo. Jakarta: Departemen Pendidikan dan Kebudayaan, 1994.

“17 Adab Mertua Terhadap Menantu - DalamIslam.Com.” Accessed December 12, 2020. https://dalamislam.com/hukum-islam/pernikahan/adab-mertuaterhadap-menantu.

DalamIslam.com. "17 Kewajiban Menantu Wanita Terhadap Mertua," November 13, 2017. https://dalamislam.com/info-islami/kewajiban-menantu-wanitaterhadap-mertua.

Arifin. Wawancara Pemuka Agama Desa Ujung Teran, February 20, 2020.

Asni. Wawancara Masyarakat Desa Ujung Teran, February 20, 2020. 